\title{
Quantifying the phantom jam externality: the case of an Autobahn section in Germany
}

\author{
Kathrin Goldmann and Gernot Sieg* (1)
}

\begin{abstract}
If not restricted by tolls, private decisions to drive on a highway result in inefficiently high usage which leads to traffic jams. When traffic demand is high, traffic jams can occur simply because of the interaction of vehicle drivers on the road, a phenomenon called phantom jam. The probability of phantom jams occurring increases with traffic flow. Unpriced externalities lead to inefficiently high road usage. We offer a method for quantifying traffic jam externalities and identifying and isolating the phantom jam externality. We examine the method by applying it to a specific highway section in Germany. The maximal congestion externality for the analyzed highway section is about 38 cents per vehicle and kilometer. Congestion charges that are calculated ignoring phantom jam externalities, can only internalize two-thirds of the true externality.
\end{abstract}

Keywords: Hypercongestion, Congestion costs, Stochastic capacity, Phantom jams, External costs

\section{Introduction}

Traffic congestion during the rush hour remains an observable phenomenon worldwide. It results in significant travel time losses for commuters, additional external environmental costs and a loss of attractiveness of the affected areas. Reasons for congestion on highways can be on the demand side, (on-ramps with high inflows or fluctuations in demand) and on the supply side (traffic accidents, construction sites, tunnels, inhomogeneous road design or simply insufficient capacity). Besides these reasons, [1-3] show that traffic jams can also occur randomly due to driving behavior. When traffic density exceeds a critical value, phantom jams may occur even in the absence of supply side reasons. Although density remains constant in their experiment, traffic is freely flowing initially, but breaks down after a while. To make the initial free flow unstable, it is sufficient that drivers on a highway merely interact with each other. For each phantom

${ }^{*}$ Correspondence: gernot.sieg@uni-muenster.de

University of Münster, Institute of Transport Economics, Am Stadtgraben 9, 48153 Münster, Germany jam, there may be a deterministic reason like tailgating, excessively fast driver reactions to speed changes, slow overtaking by a truck, slow reactions because of drivers inattentiveness or queue-jumping, but in the system, these driving errors occur stochastically and may or may not culminate in a traffic jam [4]. The probability of their causing a traffic jam increases with the saturation of the highway. For this reason, capacity cannot be considered as a fixed value, but seen rather as a stochastic concept $[5,6]$.

Whereas economists refer to the traffic state represented by the upper branch in a speed-flow diagram (see Fig. 1) as congested, because this traffic state already imposes marginal speed losses on other drivers (externalities), transportation engineering considers this traffic state as freely flowing. For economists, only the small horizontal part of the upper branch flows freely, because there is no externality. Given that, for our analysis, the section without externalities is small, we use the two terms synonymously, and refer to the upper branch as congested or as freely flowing traffic. 


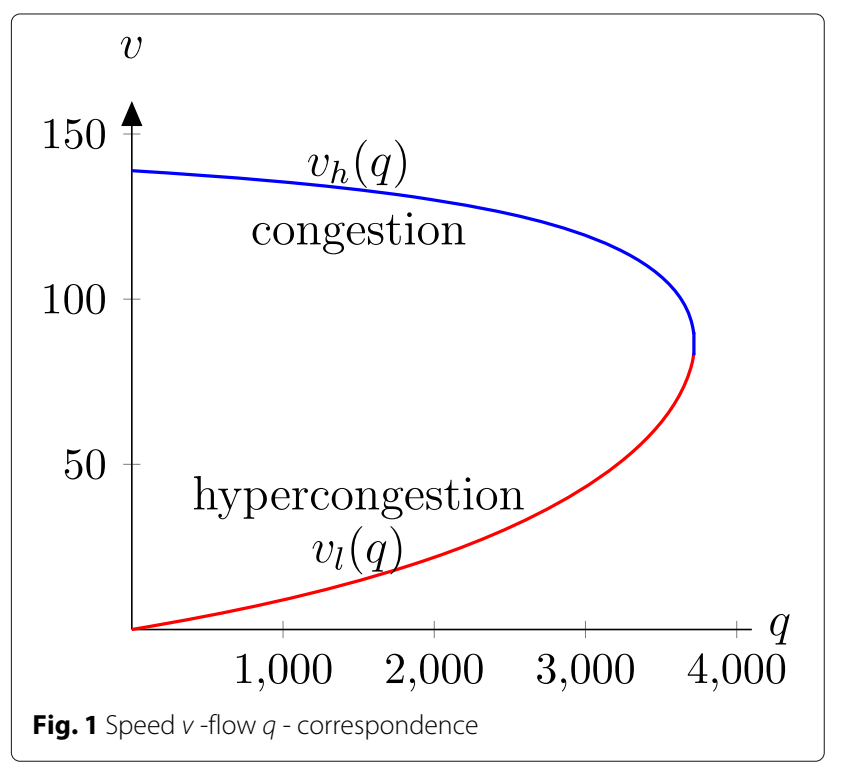

Economists refer to the traffic state represented by the lower branch as hypercongestion, whereas traffic engineering refers to it merely as congestion. To avoid confusion, we refer to the lower branch as hypercongested or jammed traffic.

Although the European Union [7, chapter 7] currently uses a speed-flow model to calculate congestion costs, such models have not been used recently in the academic literature on economic congestion modeling, because, under the assumption of deterministic road capacity, they may yield dynamically inconsistent results. Nonetheless, we show that speed-flow models do indeed provide valuable results, if a stochastic concept of road capacity is incorporated. In this paper, we thus revisit speed-flow models by incorporating stochastic road capacity and derive an average cost curve that yields dynamically consistent results. We only consider congestion costs under prevailing traffic-flow conditions and do not analyze demand reactions due to congestion charges. However, the calculated congestion costs are based on real traffic flow-data and therefore, our model can be applied to any highway section for which the respective data is available. As we consider stochastic traffic-flow breakdowns, we are able to calculate the costs of phantom traffic jams and show that these jams that are caused by driving behavior, increase the deterministic congestion costs considerably. We calculate the congestion costs over the course of a day and obtain a maximum during the peak of the rush hour of about 38 cents per kilometer. The calculated congestion costs should be internalized by means of dynamic congestion charges.

The remainder of the paper is structured as follows. The following section contains the literature review. The third section describes our theoretical model, the fourth section applies the model to German highway data and the fifth section contains a discussion while the sixth section concludes.

\section{Literature review}

Economic congestion models can be classified as bottleneck, bathtub, speed-flow and phantom jam models (see Table 1). The standard bottleneck model does not feature hypercongestion, since bottleneck capacity is independent of the length of the queue [8-11]. Modified versions of the model have been developed, in which capacity declines with the length of the queue $[12,13]$. Different tolling systems can be evaluated regarding their ability to eliminate queuing in front of the bottleneck. [14] models the bottleneck capacity as a result of queue spillovers, and if the queue is large enough, bottleneck capacity drops. [15] explore the fact that interactions between drivers can reduce the capacity of a bottleneck, and determine how tolls should be set when accounting for such stochastic capacity.

The bathtub model [16-19] analyzes urban hypercongestion at an aggregate level. In the morning rush hour, cars enter the downtown urban center and when density is sufficiently large, traffic flow becomes inefficiently low and the outflow of cars decreases, which makes hypercongestion more persistent. A time-varying toll or traffic management systems should therefore avoid hypercongestion. Some of the above mentioned models involve simulations. Generally, simulations are also performed by engineers for specific roads and road networks. For instance, [24] builds a simulation based optimization framework for an optimal time-varying pricing of toll roads. The results enable, for example, the evaluation of toll adjustments regarding their impact on changes in demand, length of peak periods or toll revenue. [25] show that macroscopic hypercongestion can occur as a purely emergent effect of dynamic equilibrium behaviour on a

Table 1 Different models of traffic congestion

\begin{tabular}{|c|c|c|c|}
\hline Model & $\begin{array}{l}\text { Main/seminal } \\
\text { authors }\end{array}$ & $\begin{array}{l}\text { Source of } \\
\text { externality }\end{array}$ & Economic policy \\
\hline Bottleneck & [11] & $\begin{array}{l}\text { demand exceeds } \\
\text { bottleneck } \\
\text { capacity }\end{array}$ & $\begin{array}{l}\text { toll to change } \\
\text { departure times }\end{array}$ \\
\hline Bathtub & {$[16,19]$} & $\begin{array}{l}\text { traffic jam at one } \\
\text { point spreads } \\
\text { into large area }\end{array}$ & $\begin{array}{l}\text { toll to reduce } \\
\text { inflow in } \\
\text { congested area }\end{array}$ \\
\hline Speed-flow & [20-22] & $\begin{array}{l}\text { other drivers } \\
\text { induce speed } \\
\text { reduction }\end{array}$ & $\begin{array}{l}\text { toll to reduce } \\
\text { number of } \\
\text { vehicles }\end{array}$ \\
\hline $\begin{array}{l}\text { Phantom } \\
\text { jam }\end{array}$ & {$[15,23]$} & $\begin{array}{l}\text { unspecified } \\
\text { driving errors } \\
\text { result in } \\
\text { stochastic traffic } \\
\text { flow break down }\end{array}$ & $\begin{array}{l}\text { toll to reduce } \\
\text { number of } \\
\text { vehicles and } \\
\text { change } \\
\text { departure times }\end{array}$ \\
\hline
\end{tabular}


network, even if the underlying link dynamics do not exhibit hypercongestion.

Speed-flow models directly use the fundamental diagram to analyze congestion and hypercongestion. However, [26] shows that in speed-flow models, hypercongestion is dynamically infeasible when considering capacity as deterministic. In order to depict hypercongestion in a static model with continuous demand, inflows onto the road must have exceeded the maximum possible inflow at some point in the past, which is inconsistent with the concept of maximum deterministic capacity. Moreover, $[26,27]$ shows that for roads without a downstream bottleneck, the average cost curve is backward-bending, and intersections with the demand curve yield multiple and unstable equilibria ${ }^{1}$.

In contrast, traffic engineers still use speed-flow models to determine the capacity of highways, for instance in Highway Capacity Manuals. To incorporate the fact that road capacity is not a fixed value, $[5,28]$ and [29] show how to implement the stochastic nature of traffic flow breakdowns.

We revisit speed-flow models by incorporating stochastic road capacity. We calculate the expected costs of congested and hypercongested traffic states. In our application, we obtain a dynamically consistent average cost curve that is not backward-bending. This is due to the fact that the probability of costly traffic hypercongestion occurring, increases with flow as well.

As we only consider congestion costs under prevailing traffic-flow conditions, we are not able to analyze demand reactions, because traffic-flow cannot be equated directly to demand. For this reason, we do not offer a complete economic model that allows for analyzing welfare gains due to congestion charges. However, speedflow data offers a very precise description of traffic situations and is available for various road sections in developed countries. We do not need to make assumptions about travel behavior, as our model can be applied directly to road sections for which respective data is available.

A stochastic capacity approach enables us to establish a static model using the speed-flow diagram. For some flow rates, there are two types of speed, congested and hypercongested, and the probability as to which of the speeds prevail depends on the flow. A driver entering the road to travel a certain distance faces a stochastic travel time, depending on the number of cars on the

${ }^{1}$ [27] also shows that hypercongestion will occur as a dynamic equilibrium phenomenon, either on a road with a queuing facility in front of its entrance or on road segments with a downstream bottleneck. This applies provided demand is sufficiently large and that in this case, the average cost curve is not backward-bending, but will eventually rise vertically. As these weaknesses hamper a reasonable economic interpretation of hypercongested traffic states of roads without a downstream bottleneck, deterministic speed-flow models have no longer been considered in recent economic research. road. The idea that the expected costs depend on two possible outcomes, congestion and hypercongestion, has been formalized by [23] for the special case of a circuit on which density is constant ${ }^{2}$. We augment the existing model to handle real highway traffic data, and incorporate the capacity drop. In a similar approach, [15] assume two possible outcomes of bottleneck capacity caused by endogenous non-recurring congestion, and also allow for an endogenous probability of breakdown, where the probability is increasing in the flow. However, they consider a bottleneck model, whereas we use the speed-flow model. Furthermore, they do not apply their approach to real data, but simulate equilibria with and without tolls.

\section{Stochastic speed-flow model}

As the famous speed-flow diagram shows traffic on a highway section can either be congested at a (high) travel speed of $v_{h}$ or jammed at a low travel speed of $v_{l}$, both depending on the flow $q$ of cars using the highway during the same time interval. Figure 1 shows $v_{h}$ as the upper branch and $v_{l}$ as the lower branch of the speed-flow correspondence.

When traffic breaks down, the input flow $q_{i}$ entering a highway section is higher than the output flow $q_{o}$ leaving the highway section because of the capacity drop. As the inflow is larger than the outflow, a queue develops, whereas when the traffic is not hypercongested, input and output flow are equal. As our underlying model is static, we need to make one assumption that makes it possible to deal with the capacity drop in this model. We assume for the lower branch that the empirical speed flow correspondence describes the output flow speed. However, the input flow describes how many cars want to use the highway section and determines the possibility of breakdowns.

If traffic does not break down, the input flow equals the output flow and the speed is $v_{h}\left(q_{i}\right)$. With probability $p\left(q_{i}\right)$, traffic breaks down and the speed is $v_{l}\left(q_{o}\right)$. [14, Table 1] presents findings from the transportation engineering literature on throughput drops, and identifies a median estimate for the size of the drop of $10 \%$ with estimates ranging as high as $25 \%$. Our estimates for the capacity drop on the highway section range from $3 \%$ to $13 \%$. We assume that there is a function $q_{c d}\left(q_{i}\right)$ which describes the capacity drop of the considered highway section, that is, the output flow $q_{o}$ if a breakdown occurs at an input flow of $q_{i}$. In the empirical part of our paper we assume that $q_{c d}\left(q_{i}\right)=0.9 q_{i}$, a ten percent capacity drop. Compared to [30], $q_{i}$ can be considered as the pre-queue capacity.

\footnotetext{
${ }^{2}[1,2]$ and [3] show experimentally that traffic jams can occur on a circuit even if the number of cars is constant and therefore demand is fixed.
} 
To summarize, in our model, the travel speed depends on $q_{i}$ and is either high (but congested) $v_{h}\left(q_{i}\right)$ with probability $1-p\left(q_{i}\right)$ or low (and jammed) $v_{l}\left(q_{c d}\left(q_{i}\right)\right)$ with probability $p\left(q_{i}\right)$. Because the expected speed depends only on the input flow, we drop the subindex $i$ below and only write $q$ for the input flow.

The expected travel speed can be written as

$$
E_{v}(q)=p(q) v_{l}\left(q_{c d}(q)\right)+(1-p(q)) v_{h}(q) .
$$

The marginal speed losses that an additional driver imposes on subsequent drivers can be written as

$$
\begin{aligned}
\frac{d E_{v}}{d q}= & \frac{d v_{h}}{d q}-\frac{d p}{d q}\left(v_{h}(q)-v_{l}\left(q_{c d}\right)\right) \\
& -p(q)\left(\frac{d v_{h}}{d q}-\frac{d v_{l}}{d q_{c d}} \frac{d q_{c d}}{d q}\right) .
\end{aligned}
$$

Eq. 2 can be split into two parts. The first term is the normal speed loss due to congestion $\left(d v_{h} / d q\right)$, while the second is the hypercongestion adjustment that incorporates the probabilities of a traffic jam.

To simplify matters we ignore drivers' heterogeneity and that commuters prefer reliable highway travel [31-33] but assume homogenous and risk neutral drivers. Travel time costs $c$ then depend only on the speed, which in turn depends on the number of vehicles per hour, and the expected travel time costs $C$ of a driver are

$$
C(q)=p(q) c\left(v_{l}\left(q_{c d}(q)\right)\right)+(1-p(q)) c\left(v_{h}(q)\right) .
$$

When we assume homogenous drivers, these costs are the average costs of all vehicles ${ }^{3}$.

Social costs are $S C=q \cdot C(q)$ and marginal social costs are $M S C=C+q \cdot d C / d q$. The external effect (on other drivers), which is not taken into account by individual drivers, is $q \cdot d C / d q$. The marginal external travel time costs are:

$$
\begin{aligned}
q \frac{d C}{d q}= & q\left[(1-p) \cdot \frac{d c}{d v} \frac{d v_{h}}{d q}+p \cdot \frac{d c}{d v} \frac{d v_{l}}{d q_{c d}} \frac{d q_{c d}}{d q}\right. \\
& \left.+\frac{d p}{d q}\left(c\left(v_{l}\left(q_{c d}\right)\right)-c\left(v_{h}(q)\right)\right)\right] .
\end{aligned}
$$

Considering a distance of $s$ and a value of time of $t, c(v)=$ $t s / v$ and $d c / d v=-t s / v^{2}$, Eq. 4 can be written as:

$$
\begin{aligned}
q \frac{d C}{d q}= & q\left[(1-p) \cdot \frac{(-t s)}{v_{h}^{2}} \frac{d v_{h}}{d q}-p \cdot \frac{t s}{v_{l}^{2}} \frac{d v_{l}}{d q_{c d}} \frac{d q_{c d}}{d q}\right. \\
& \left.+\frac{d p}{d q}\left(\frac{t s}{v_{l}}-\frac{t s}{v_{h}}\right)\right] .
\end{aligned}
$$

Rearranging Eq. 5, yields the congestion and hypercongestion costs

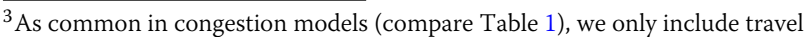
time costs. Further research and other types of models are needed to extend calculations to other internal or external cost components.
}

$$
\begin{aligned}
q \frac{d C}{d q}= & \underbrace{-q t s\left[\frac{1}{v_{h}^{2}} \frac{d v_{h}}{d q}\right]}_{\text {Deterministic congestion costs }} \\
& \underbrace{-q t s\left[p\left(\frac{1}{v_{l}^{2}} \frac{d v_{l}}{d q_{c d}} \frac{d q_{c d}}{d q}-\frac{1}{v_{h}^{2}} \frac{d v_{h}}{d q}\right)+\frac{d p}{d q}\left(\frac{1}{v_{h}}-\frac{1}{v_{l}}\right)\right]}_{\text {Stochastic hypercongestion adjustment }} .
\end{aligned}
$$

The first term of Eq. 6 represents the congestion costs due to speed losses on the upper branch of the speed-flow curve in a deterministic setting (Deterministic congestion costs). The second term incorporates the probabilities that come into play in a stochastic setting (Stochastic hypercongestion adjustment). As congested traffic only prevails with probability $1-p$, the congestion effect is overestimated in a deterministic setting insofar as the congestion effect in a deterministic setting is assumed to apply all the time. The term $\left(p \cdot\left(-1 / v_{h}^{2} \cdot d v_{h} / d q\right)\right)$ in the hypercongestion adjustment corrects this. The term $\left(1 / v_{l}^{2} \cdot d v_{l} / d q_{c d} \cdot d q_{c d} / d q\right)$ in the hypercongestion adjustment displays the marginal costs in hypercongested traffic, and the last term $\left(d p / d q \cdot\left(1 / v_{h}-1 / v_{l}\right)\right)$ shows the expected speed losses due to phantom traffic jams.

The part labeled stochastic hypercongestion adjustment therefore augments the speed-flow model for hypercongested traffic states and thus incorporates a traffic state that could not have been analyzed with the earlier deterministic speed-flow models. If one wants to exclude the capacity drop, $q_{c d}$ can be set equal to $q$, which eliminates the corresponding derivative in Eq. 6.

Expected average travel time costs are increasing in $q$ if $d C / d q>0$ which depends on the specific functions that describe the road section, but is independent of time costs and distance travelled.

\section{Application to traffic data of the highway A42}

Similar to the U.S. Highway Capacity Manual, the German Highway Capacity Manual (HBS) describes the design capacities of highways and provides standardized methodologies and values for evaluating the performance of highway sections. Underlying research for the HBS comprises amongst others, the specification of the functional forms describing the speed-flow relationships, as well as the functional form of the distribution of the traffic flow breakdown probability. To calculate the effects of Eq. 6, we need to know those functional forms. With this knowledge we are able to calculate the expected marginal speed losses depending on the number of cars traversing the highway section. For this reason, we apply the same methodology as in the HBS following $[5,29,34,35]^{4}$.

\footnotetext{
${ }^{4}$ As we want to give an example how to use our theoretical model to calculate congestion costs, we keep the calculation quite simple. We are aware of the fact, that more sophisticated methods are available for example for the calculation of the breakdown probability.
} 


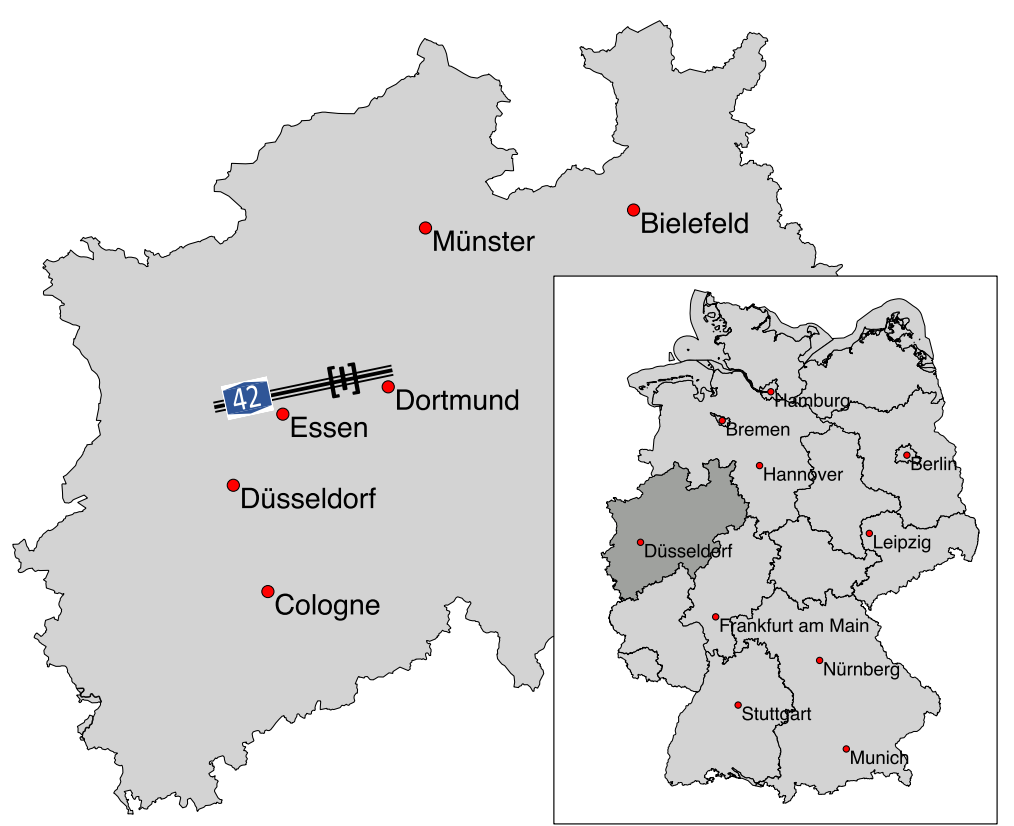

Fig. 2 Location of highway and traffic sensor [l]

\subsection{Data}

We use traffic data for the highway section 44092161 from Straßen.NRW for the highway A42 which is located in the northern Ruhrgebiet in North Rhine-Westphalia (see Fig. 2). The highway section lies in a metropolitan area and has two lanes and the speed limit is $100 \mathrm{~km} / \mathrm{h}$. We employed data for 5 -min intervals covering the flow in veh/5 $\mathrm{min}$, speed in $\mathrm{km} / \mathrm{h}$ and the density in veh $/ \mathrm{km}$. Speed and flow are available separately for cars and trucks. Local speeds are converted into space mean speeds following [29].

As the highway capacity depends on weather conditions and the amount of daylight, we match the traffic data with weather and sunrise and sunset data ${ }^{5}$. By doing so, we can exclude all intervals where road capacity was below the maximum possible capacity. Rain, darkness and frost, for instance, influence road capacity negatively. In addition, this information can also be used directly to analyze the impact of weather conditions on external costs ${ }^{6}$.

\subsection{Functional forms of speed-flow relationships}

The fundamental relationship describes the relation between flow $q$, density $k$ and space mean speed $v$. [36] compare the performance of eight different functional forms in modelling different traffic regimes. They find

\footnotetext{
${ }^{5}$ Data on rainfall and temperatures are from the Deutscher Wetterdienst, Germany's national meteorological service, and sunrise and sunset data are taken from the webpage: https://www.timeanddate.de/sonne/deutschland/ muenster? monat $=1$ \&year $=2015$.

${ }^{6} \mathrm{~A}$ figure that shows how rain and darkness increase the marginal external costs is provided in the Appendix: Additional costs caused by rain and darkness.
}

that each model has certain advantages in representing specific traffic regimes, but fails to represent others. [37, 38] compare Greenshield's single-regime, Pipe's two-regime and Van Aerde's single-regime model. They demonstrate the shortcomings of Greenshield's and Pipe's models in capturing the entire range of traffic stream situations. They find that the four-parameter Van Aerde model is able to reflect different traffic situations on different road types, as it best approximates the field data. Van Aerde's ([39]) model describes the speed-density relationship by means of the minimum distance headway between consecutive vehicles. In a stable relationship between traffic density, traffic flow and space mean speed, the Van Aerde model can be written as

$$
q(v)=\frac{v}{c_{1}+c_{2} /\left(v_{0}-v\right)+c_{3} v},
$$

where $c_{i}$ are parameters of the function and $v_{0}$ is the speed at a flow or density of zero. The Van Aerde function is backward-bending and each value of $q$ can be assigned to one speed of congested $v_{h}$, as well as to one speed of hypercongested $v_{l}$ traffic. [29] analyze traffic flows on German highway segments in order to revise the design capacities. They found that the Van Aerde model provides the best fit for highway sections where hypercongestion occurs ${ }^{7}$. For this reason, we calibrate the

\footnotetext{
7 To obtain good estimates for the Van Aerde model, further data cleansing is necessary, such as removing intervals with temporary obstacles. Moreover, all data points where the standard deviation of the speed travelled in the 5-min intervals and in the corresponding 60-min interval exceeded a value of 10, are removed for the estimation of the speed-flow relationship. The data cleansing is described in both $[5,29]$.
} 
four parameters $\left(c_{1}, c_{2}, c_{3}, v_{0}\right)$ of the Van Aerde function, minimizing the squared errors with respect to speed, flow and density following [29]. The parameters are displayed in Table 2 in the appendix. The model is also employed by [40] to calculate link-specific free flow travel times.

\subsection{Probability of traffic flow breakdowns}

In the fundamental diagram, coming from very low traffic flows corresponding to high speeds, the more cars use this highway section per hour, the greater the probability that the traffic will break down. It is widely accepted in the literature that the breakdown flow/density has properties of a random variable [5, 6, 41, 42]. Focusing on highway capacity analysis, $[5,29]$ use the non-parametric Product Limit Method of [43] to calculate the breakdown probabilities. The method builds on the idea that for high traffic flows, it is possible to observe either freely flowing/congested traffic or hypercongested traffic in the next interval ${ }^{8}$. For this reason, it is possible to calculate the number of intervals with an observed traffic volume of $q$ which are not followed by traffic breakdowns (censored intervals), and the number of intervals with traffic volume $q$ that are indeed followed by a traffic flow breakdown in the next interval. Inserting this information into the Product Limit Function, enables calculating the breakdown probability. Applying the Product Limit Method to traffic data requires defining a threshold speed, above which traffic is congested/freely flowing, and below which traffic is hypercongested with stop-and-go patterns. [5] found out that a threshold speed of $70 \mathrm{~km} / \mathrm{h}$ is representative for German highways. For this reason, we follow $[5,44]$ and also employ a threshold speed of $70 \mathrm{~km} / \mathrm{h}^{9}$.

[5] found that the normal Weibull distribution best fits the non-parametric distribution function of the investigated German motorway sections. The distribution function of the Weibull distribution has the following form:

$$
F(q)=1-e^{-(q / \beta)^{\alpha}},
$$

where $q$ is the traffic volume, $\alpha$ is the shape parameter and $\beta$ is the scale parameter. We follow the approach of [5] to determine the distribution of traffic flow breakdowns.

As breakdowns of traffic flows occur suddenly, only short time intervals are appropriate for analyzing traffic breakdowns. The time intervals employed in the empirical literature vary between 1-minute [45] and 10-minute intervals [44]. We follow [5, 29], who use 5-min intervals to estimate the parameters of the Weibull distribution. By assuming that the variance of the traffic flow is normally distributed over the interval, it is possible to convert

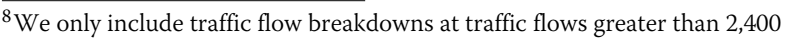
vehicles per hour. With lesser flows, traffic breakdowns are probably caused by bottlenecks.

${ }^{9}$ In robustness analyses we found out, that changes in the threshold speed within a range between 60 and $80 \mathrm{~km} / \mathrm{h}$ only marginally affect the shape of the probability distribution function.
}

the Weibull distribution function to hourly intervals. The procedure is described in detail in [5], and is necessary, as the capacity estimation with the Van Aerde function and the calculation of time costs also builds on hourly data. The parameters are presented in Table 2 in the appendix. Figure 3 shows the speed-flow relationship and the Weibull distribution functions. The breakdown probability distribution function for hourly intervals is shifted inwards, as the probability that traffic flow will break down within the next hour is ceteris paribus higher than the probability that the traffic flow will break down within the next five minutes. The displayed distribution functions were calculated including all weather and light conditions. Breakdown probabilities would increase ceteris paribus if only time intervals with, for example, rainfall were considered for calculation.

Knowing the functional forms of the speed-flow relationships and the breakdown probabilities, we are able to calculate the external costs. The functional form of the Van Aerde function allows for calculating the marginal speed changes caused by additional drivers on the road per hour (from $q$ to $q+1$ ). The distribution function of the breakdown probability yields the probability of the traffic states of congestion or hypercongestion prevailing. More precisely, the breakdown probability measures the probability that the traffic flow will break down in the next interval given the traffic flow in this interval. However, using this probability for the traffic state of hypercongestion is not entirely correct as at this traffic state, flow has already broken down in previous intervals. As the hypercongested intervals are quite short in our data (approximately 14 minutes), the error we make using the breakdown probability also for the state of hypercongestion is small. Furthermore, each additional driver using the road per hour, marginally increases the probability of a breakdown. For this reason, we also need to investigate the changes in $p$ for increases from $q$ to $q+1$.

\subsection{Capacity drop}

The capacity drop has received considerable attention in transportation science literature. It describes the observation that the discharge rate of hypercongested traffic is lower than the maximum flow in congested but freely flowing traffic [30,46]. At a traffic breakdown, in our model, the traffic state simply switches from the congested to the hypercongested branch. The capacity drop renders the hypercongested traffic state more persistent, because, due to the lower traffic flow, traffic demand has to fall to a much lower level to dissolve the traffic jam [47].

Research has tended to concentrate on the mechanism of the capacity drop phenomenon at bottlenecks, taking into account various aspects like the impact of driving behavior [48], the existence of lane-drops, on-ramps with 


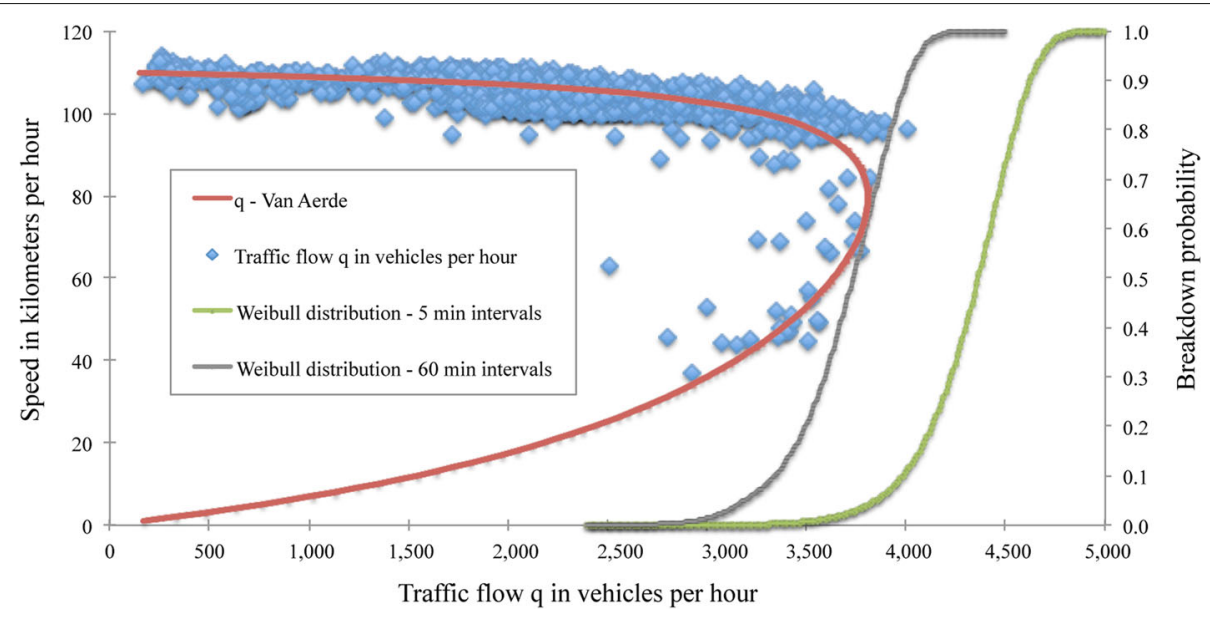

Fig. 3 Van Aerde Function and Weibull Distribution for the A42 (westbound)

or without ramp controls $[49,50]$ or the impact of different jam types like standing queues or stop-and-go waves, e.g. [30]. The results of [30] indicate that the outflow of stop-and-go waves is lower than those of standing queues. As stop-and-go waves are especially relevant for phantom jams, their results indicate the importance of this phenomenon in this context.

Estimates of the capacity drop range between 3\% and $18 \%$, with [49] obtaining this entire range of estimates. $[46,50]$ have estimates in the medium range of $6 \%$ and $15 \%$ respectively. The US [51] recommends $7 \%$ as a default value. [52] augments the Van Aerde Model by an additional parameter, so as to take the capacity drop into account and applies it to German highway data. He finds that capacity drops by $11 \%$ when the traffic flow breaks down. [14, Table 1] presents findings of transportation engineering literature about throughput drops and identifies a median estimate for the size of the drop of $10 \%$ with estimates ranging as high as $25 \%$.

Our estimates for the capacity drop on the highway section range from $3 \%$ eastbound to $13 \%$ westbound. As the studies cited in the previous paragraph perform more extensive and sophisticated research on the extent of capacity drops than is done in this paper, we simply assume a medium value of $10 \%$ in our calculations. Within the framework of our model, we assume that the capacity drop only affects hypercongested traffic states. When traffic breaks down, we assume a $10 \%$ flow loss and therefore, the shift from the upper to the lower branch occurs diagonally, resulting in even greater speed losses. For this reason, we use the Van Aerde function for the whole range of traffic situations and do not estimate the upper and the lower branch separately, as do [53]. We also assume that in the state of hypercongestion, the traffic flow is $10 \%$ lower, so that the dissolution of traffic jams is less efficient.

\subsection{Travel time costs}

Following the German guidelines for infrastructure planning, we differentiate between three different travel time cost categories. There are private trips (for shopping, leisure activities or driving to the workplace and back), business trips (during working hours) and trips of heavyduty vehicles (trucks). The German methodology handbook for the federal infrastructure plan differentiates between private and business time cost parameters, with both increasing in total trip length [65, pp. 97-101] ${ }^{10}$. The study "Mobility in Germany" contains the average car trip lengths, as well as the trips broken down by purpose [66, p. 28, p. 89]. However, the results include all trips and not just those on highways. For this reason, we made the assumption that the average private trip length of approximately $18 \mathrm{~km}$ is somewhat greater for trips on highways $(45 \mathrm{~km})$. This assumption is necessary, because, as mentioned above, the value of time function is upward-sloping with the trip length. The corresponding time costs are 8.17 Euro/h. The average length of business trips on highways is assumed to be $100 \mathrm{~km}$ (time costs: 30 Euro/h) [65, pp. 97-101].

There are basically two types of heavy-duty vehicles on the road: normal trucks and semi-trailer trucks. Due to different trip lengths and vehicle specifications, the drivers' wages (17.64 and 20.14 Euro/h) and the capacity maintenance costs (5.81 and 9.34 Euro/h) differ [65, pp.

\footnotetext{
${ }^{10}$ There is evidence that values of travel time are higher in heavily-congested traffic than under free-flow conditions because stop-and-go driving is frustrating [55-57] Allowing for this effect would increase the marginal external costs of congestion. Slower highway traffic induces progressively fewer severe accidents [58] as well as a better environmental performance [59]. However, this statement only holds unambiguously, if the number of vehicles remains unchanged. We analyze an increase in traffic density that may result in reduced fast traffic, but the overall effect on accidents and environment is ambiguous. We therefore do not include this externality in our calculation. Furthermore, these externalities may already be internalized by existing gasoline taxes [60].
} 
133-134]. Moreover, the methodology handbook also offers an average value of time for transported goods of $6.88 \mathrm{Euro} / \mathrm{h}$, with an average loading factor of 0.7 [65, p. 101]. The total time costs for normal trucks are therefore assumed to be 28.27 Euro/h and 34.30 Euro/h for semitrailer trucks. On this highway section, among heavy-duty vehicles, the shares of normal trucks versus semi-trailer trucks are approximately $2 / 3$ versus $1 / 3$, which yields an average time cost value for heavy duty vehicles of 30.28 Euro/h.

The shares of trips by purpose are also from the Mobility in Germany study, although the trip purposes, including routes on highways may differ from those within urban centers. However, detailed data for highway trips is not available. The same applies to the average rate of vehicle occupancy for cars, to which we apply a value of $r_{V O}$ of $1.1[54$, p. 8]. The cost factors are weighted by the share of private $\left(w_{p}\right)$, business $\left(w_{b}\right)$ and heavy duty vehicle $\left(w_{h d}\right)$ trips.

As the time costs of 8.17, 30.00, and 30.28 Euro/h for private, business, heavy-duty vehicle-trips respectively, are given in prices with base year 2012, the GDP deflator has been applied to extrapolate them to $2019^{11}$. The time cost parameters employed in the cost calculations therefore equal 9.22, 33.87, and $34.18 \mathrm{Euro} / \mathrm{h}$ respectively.

It should be noted that the congestion effect corresponding to the upper branch of the speed-flow curve, barely affects heavy-duty vehicles, as their maximum permissible speed in Germany is 80 kilometers per hour. They do not incur significant travel time prolongation in congested traffic on the upper branch of the speed-flow curve $^{12}$. The travel time cost parameter $c_{c o n}$ is:

$$
c_{c o n}=w_{p} \cdot r_{V O} \cdot 9.22 €+w_{b} \cdot r_{V O} \cdot 33.87 €=13.40 €,
$$

where the weights are $w_{p}=0.88$ and $w_{b}=0.12$.

The hypercongestion externality is relevant for all vehicles on the highway, including heavy-duty vehicles. For this reason, the weights are somewhat different at $w_{p}=$ $0.77, w_{b}=0.10$ and $w_{h d}=0.13$.

$$
\begin{aligned}
c_{\text {hyper }} & =w_{p} \cdot r_{V O} \cdot 9.22 €+w_{b} \cdot r_{V O} \cdot 33.87 € \\
& +w_{h d} \cdot 34.18 €=15.98 €
\end{aligned}
$$

Evaluating the travel time losses due to the normal congestion effect and those due to hypercongestion with the cost parameters, enables us to calculate external congestion costs that depend on the current traffic flow situation.

\footnotetext{
${ }^{11}$ The GDP deflator is taken from the Destatis Genesis Database, time series no. 81000-0033.

${ }^{12}$ As the apex of the Van Aerde function is at a speed of $70 \mathrm{~km} / \mathrm{h}$ (eastbound) and $80 \mathrm{~km} / \mathrm{h}$ (westbound), we accept a small error with the assumption that heavy duty vehicles are not affected by travel time prolongation on the upper branch. However, we believe that the error is small and that travel time losses in congested traffic are primarily an issue for cars.
}

\subsection{Results}

Figure 4 shows the total expected private, marginal and social travel time costs (without and with capacity drop) that have been calculated with the above mentioned time cost parameters.

The expected average costs curve (blue line) is upwardsloping. However, compared to the external costs, the slope is quite moderate, underlining the importance of internalizing the external costs in order to obtain socially acceptable quantities.

Figure 5 shows the marginal external cost functions for the highway section with and without capacity drop (indicated with $\mathrm{CD}$ ). The effects are split as in Eq. 6 in the deterministic congestion effect (blue - dotted) and the stochastic hypercongestion adjustment (red - striped). As the cost functions display the expected costs of a specific traffic volume $q$, they increase monotonously in $q$.

The upward-sloping cost curve and the surge at very high traffic flows are driven by three factors:

1 The more vehicles that want to use the road at the same time, the more other vehicles are affected by travel time losses. If marginal effects were constant over the entire traffic flow range, this would result in a linearly increasing cost function.

2 However marginal effects of additional drivers are not constant over the entire traffic flow range, as the slope of the Van Aerde function at the apex is much steeper than at low traffic flows.

3 The probability that the traffic flow breaks down increases with flow, and therefore, the costs of the shift from congested to hypercongested traffic become more relevant at higher traffic flows. This overcompensates for the fact that the absolute speed losses due to breakdowns decrease with $q$.

These marginal cost functions enable us to assign corresponding costs to each traffic flow observed on the highway. Our next step is thus to use the observed traffic flow for an average Thursday (public and school holidays excluded) at this highway section of the A42 (see Fig. 6).

Figure 7 shows the external congestion costs (blue dotted), as well as the hypercongestion adjustment (red - striped). It is evident that at peak times, due to the increase in probability of a traffic breakdown, the costs of hypercongestion become more pronounced, whereas in off-peak times, these costs equal zero. More precisely, when the flow exceeds approx. $65 \%$ of design capacity flow (striped line in Fig. 6), the hypercongestion costs start to increase. This effect becomes especially relevant when the capacity drop is taken into account as well (Fig. 7b and d).

In off-peak periods, the probability of a random breakdown is close to zero, as driver errors, except for those causing accidents and thereby bottlenecks, do not affect 


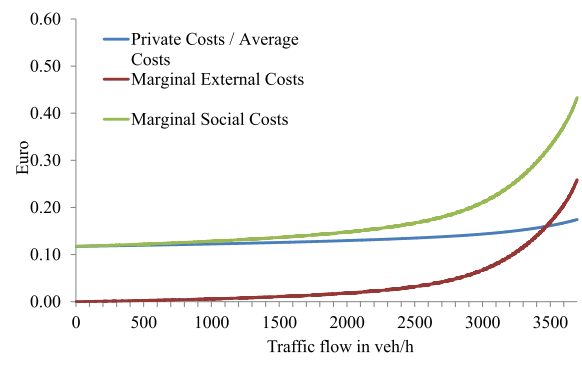

(a) A42 eastbound

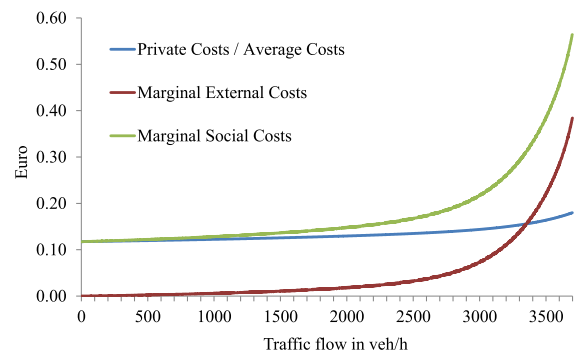

(b) A42 eastbound - with CD

Fig. 4 Cost functions. (a) A42 eastbound, (b) A42 eastbound - with CD

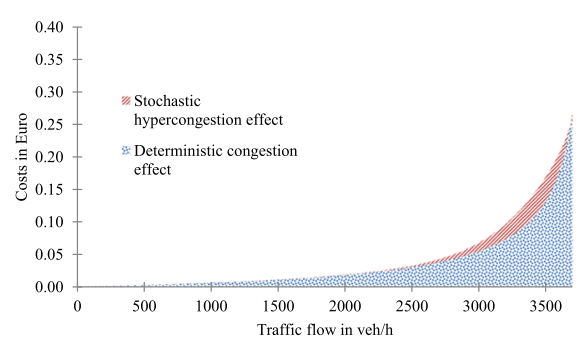

(a) A42 eastbound

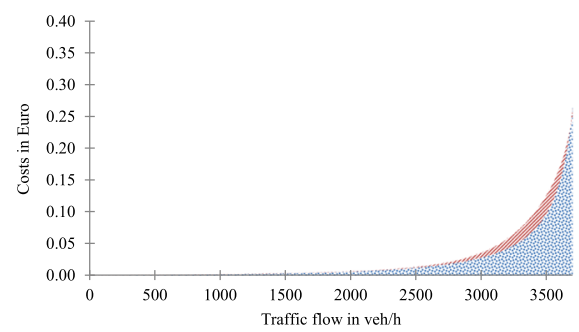

(c) A42 westbound

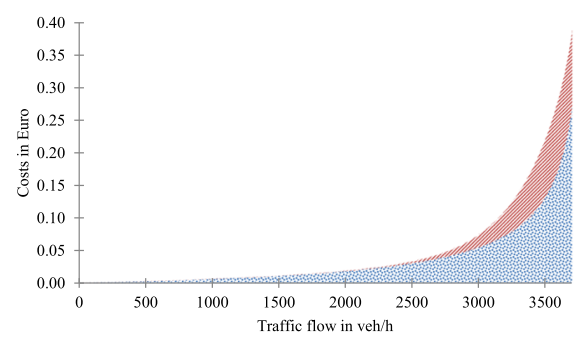

(b) A42 eastbound - with CD

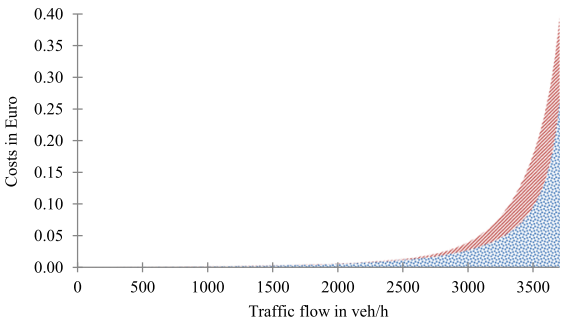

(d) A42 westbound - with CD

Fig. 5 Marginal external costs without (left) and with (right) capacity drop. (a) A42 eastbound, (b) A42 eastbound - with CD, (c) A42 westbound, (d) A42 westbound - with CD

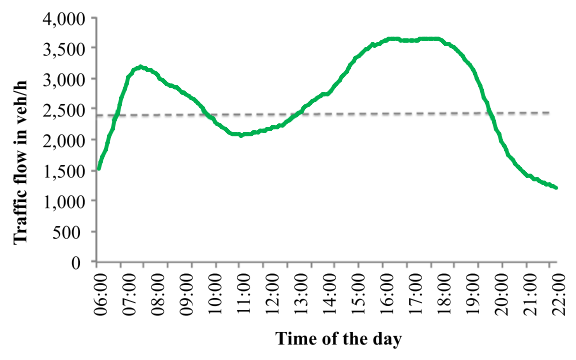

(a) A42 eastbound

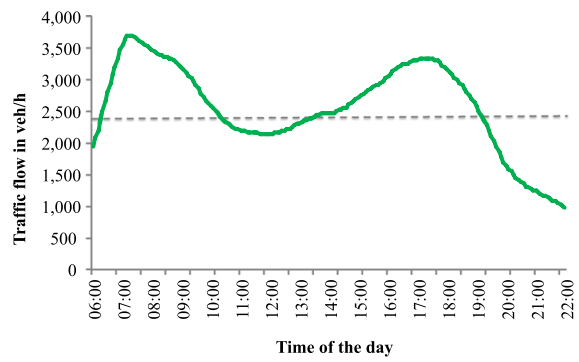

(b) A42 westbound

Fig. 6 Traffic flow on an average Thursday. (a) A42 eastbound, (b) A42 westbound 


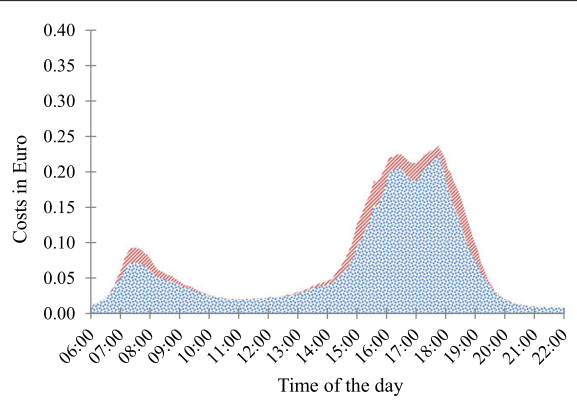

(a) A42 eastbound

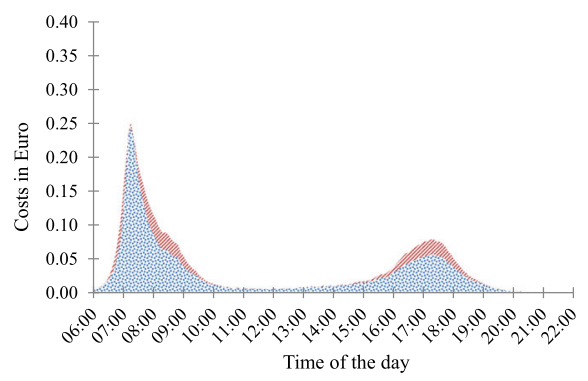

(c) A42 westbound

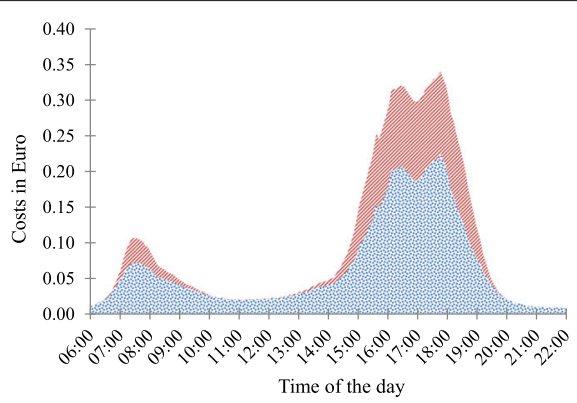

(b) A42 eastbound - with CD

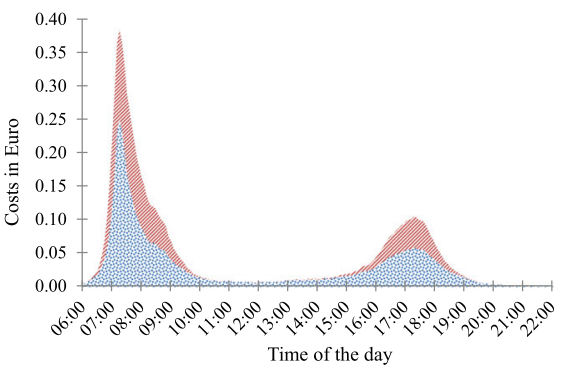

(d) A42 westbound - with CD

Fig. 7 External congestion costs (blue) and hypercongestion adjustment (red). (a) A42 eastbound, (b) A42 eastbound - with CD, (c) A42 westbound, (d) A42 westbound - with CD

the stability of the traffic flow up to a certain saturation level and therefore, the hypercongestion externality is zero as well. Traffic breakdowns at low traffic flows are caused by bottlenecks and should therefore be analyzed with bottleneck models.

In Fig. 8 in Appendix: Additional costs caused by rain and darkness we use the information on different weather and daylight conditions to show that this information influences traffic flow conditions and thus also congestion costs. Using only time intervals without daylight and with rainfall, the breakdown probability function shifts inwards and thus the undesired traffic state of hypercongestion becomes more likely. This increases the marginal costs by approximately 8 cents in the afternoon peak on the A42 eastbound compared to Fig. 7b. Contrarily, if only favorable weather and light conditions are included in the calculation, external costs would be lower compared to the baseline case.

In total, we identify a currently non-internalized congestion externality for this highway section of a maximum of about 38 cents per vehicle and kilometer. The average externality ranges roughly between 1.6 and 4.6 Euro cents, when costs are spread equally over all intervals. More precisely, the average externality in the eastbound direction lies between 3.7 and 4.6 Euro cents without and with capacity drop respectively. On the westbound section the average externality, ranging within 1.6 and 2.0 Euro cents, is lower due to fewer hours of traffic congestion. The values may be on average large enough to justify a congestion charge, when considering the costs of the charging technology of arguably 2.5 Euro cents per kilometer. If this is not the case yet, as the values of the westbound direction might suggest, decreasing costs of the charging technology and increasing congestion will probably make congestion charges profitable in future.

\section{Discussion}

The absolute size of the external costs we obtain can only be taken as a reference value for other highway sections, because they are very specific to the respective traffic situations. The results depend on the estimated speedflow relation and the breakdown probability, and these can be very different among different highways and highway sections. The highway section that we consider, for example, has a speed limit of $100 \mathrm{~km} / \mathrm{h}$. Therefore, the congestion externality of a car tends to be rather small, compared to sections with no speed limits, because the free flow velocity does not legally exceed $100 \mathrm{~km} / \mathrm{h}$. In general, the lower the speed differences between different cars on the highway, the more stable is the traffic flow. Therefore, speed limits tend to smoothen out the traffic and therefore reduce the probability of phantom jams. Because the hypercongestion externality depends on 
both the value of the breakdown probability and the marginal breakdown probability, the overall effect on the hypercongestion externality is ambiguous. Because travel time costs are relatively higher in hypercongestion [55-57], and commuters may be risk avers and prefer reliability [31-33], using the values of the German methodology handbook for the federal infrastructure plan, we rather underestimate the hypercongestion externality.

Autonomous cars will increase the capacity of a highway as well as reduce the occurrence of phantom jams [61]. Vehicle to vehicle (V2V) communication transmits information between vehicles on the road in realtime, enables the anticipation of other cars' actions and contributes to the stability of traffic flow. While it is not clear how autonomous cars and traditional drivers would interact, especially because we do not know how the autonomous cars will be programmed or how the artificially intelligent car [62] will react to traditional drivers, autonomous cars should be able to avoid facilitating phantom jams, and may therefore be exempt from phantom jam tolls. In a perfect world of autonomous cars, there should be no phantom jams and thus no longer any phantom jam externality. Therefore, the aggregated value of the phantom jam externality calculated in this paper can be used as approximation of the value autonomous cars generate by avoiding phantom jams.

The extent of congestion and hypercongestion costs are highly specific, so that future research should include an analysis of more highway sections with different characteristics regarding the number of lanes or the speed limit, so as to determine which aspects affect external costs. These calculations can also be extended to the entire highway 42 because, for instance, traffic detectors are located every 2.5 kilometers on this highway.

\section{Conclusion}

Especially in metropolitan areas, highways are congested during the rush hour. Travel times increase significantly due to congestion, and the resulting additional time and environmental costs place a large burden on economies. There are several possible reasons for congestion at a specific site, but one that is relatively independent of a specific location or road design, is the driving behavior. Driving behavior is, however, the main reason for phantom traffic jams.

Following [2], we also assume that there are random traffic jam formations that are not caused by bottlenecks. Departing from traffic experiments with stochastic traffic flow breakdowns, we set up a model for calculating their external costs. We show that considering capacity as deterministic ignores parts of the externality, which we refer to as stochastic hypercongestion adjustment.

Directly using the speed-flow data, we calculate external congestion and hypercongestion costs for a German highway section. By incorporating the probabilities in the speed-flow model, we obtain a cost function that increases monotonously with flow and is not backward-bending, as in deterministic speed-flow models. For this reason, a unique cost value can be assigned to each level of traffic flow.

Our results indicate that the stochastic hypercongestion adjustment is not negligible, especially when considering the capacity drop due to traffic flow breakdowns. We show that the costs caused by stochastic traffic flow breakdowns can increase the deterministic congestion costs by up to $50 \%$.

In order to calculate not only externalities, but also Pigouvian congestion charges, our approach has to be combined with a demand model. Because, in our application, the cost function is increasing, a unique equilibrium should exist. In this congestion (and hypercongestion) charge equilibrium, congestion externalities will be reduced, and our maximum value of the externality (of about 0.38 Euro per $\mathrm{km}$ ) could be considered as an upper bound of the equilibrium congestion charge. If a congestion charge were imposed, drivers would adjust their departure time, route choice or travel mode, such that traffic flow over the course of the day would change and the marginal external cost (observed at a fixed time of the day) would change too. If users change their travel behaviour to avoid the peak-charges, and congestion charges are indeed all about such changes, the peak-period externality and corresponding congestion charge would decrease. The peak period might grow in terms of duration, but should decline in terms of intensity. Therefore, the equilibrium charge may be lower at the maximum, but higher at the previous off-peak times.

In our model, we also assume that all drivers are equal. Trucks, however, are longer, slower, and heavier, and therefore warrant special treatment and impose higher external congestion costs [63]. Based on [64], who finds that many of the critical parameters of the flow-density relationship depend on vehicle length, future research should separate the external effects of trucks and cars on travel times, so as to determine vehicletype-dependent external costs that could, in a next step, be used to calculate congestion and hypercongestion charges.

\section{Appendix}

Calibrated parameters 
Table 2 Parameters and values used for application

A42

Eastbound

A42

Westbound

van Aerde Model

$c_{1}$

0.007521

0.004880

$c_{2}$

$c_{3}$

$v_{0}$

Weibull-distribution

60-min intervals, baseline case

$\alpha$

$\beta$

Weibull-distribution

60-min intervals, rain and darkness

$\alpha$

$\beta$

Travel time cost parameters in Euro ${ }^{a}$

Effects involving the congested branch

Effects involving the hypercongested branch

a Own calculations based on $[65,66]$
0.475520

0.092570

0.000001

0.000163

114.1

110.0

13.82

16.55

4377

4388

16.07

18.49

4162

4331
13.40

15.98

\section{Additional costs caused by rain and darkness}




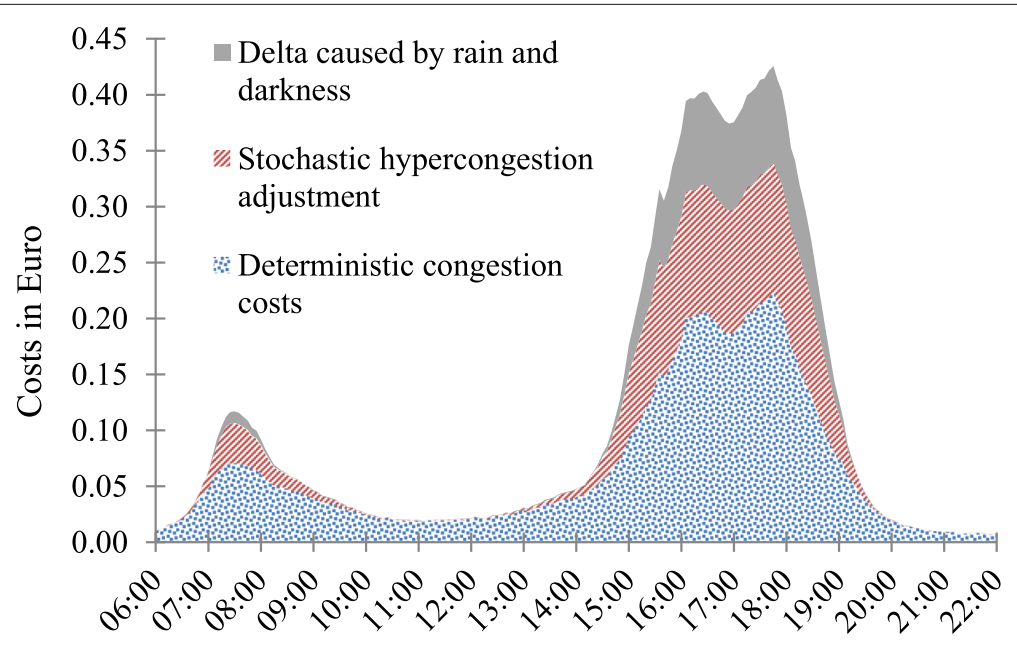

Time of the day

Fig. 8 A42-eastbound: Additional costs depending on outside conditions 


\section{Acknowledgements}

We are grateful for helpful comments from two anonymous referees and participants at the annual meetings of the International Transportation Economics Association and Brian Bloch for his editing services.

\section{Authors' contributions}

All authors declare that they have participated sufficiently in the work to take public responsibility for appropriate portions of the content.

All Authors give final approval of the version to be submitted and any revised version.

Individual Contribution are 1. Paper conception and design: Kathrin

Goldmann and Gernot Sieg 2. Development of theoretical model: Gernot Sieg 3. Analysis and interpretation of model: Kathrin Goldmann and Gernot Sieg 4. Acquisition of data: Kathrin Goldmann 5. Analysis and interpretation of data: Kathrin Goldmann 6. Drafting of manuscript: Kathrin Goldmann and Gernot Sieg 7. Critical revision: Kathrin Goldmann and Gernot Sieg The overall shares of contributions are: Kathrin Goldmann 50\% Gernot Sieg $50 \%$

\section{Funding}

No external funding. Open Access funding enabled and organized by Projekt DEAL.

\section{Availability of data and materials}

The datasets used and/or analysed during the current study are available from the corresponding author on reasonable request.

\section{Competing interests}

There are no competing interests.

Received: 26 August 2020 Accepted: 26 December 2020

Published online: 05 February 2021

\section{References}

1. Nakayama A., Fukui M., Kikuchi M., Hasebe K., Nishinari K., Sugiyama Y., Tadaki S., Yukawa S. (2009) Metastability in the formation of an experimental traffic jam. New Journal of Physics 11:083025

2. Sugiyama Y., Fukui M., Kikuchi M., Hasebe K., Nakayama A., Nishinari K., Tadaki S., Yukawa S. (2008) Traffic jams without bottlenecks experimental evidence for the physical mechanism of the formation of a jam. New Journal of Physics 10:033001

3. Tadaki S., Kikuchi M., Fukui M., Nakayama A., Nishinari K., Shibata A. Sugiyama Y., Yosida T., Yukawa S. (2013) Phase transition in traffic jam experiments on a circuit. New Journal of Physics 15:103034

4. Schönhof M., Helbing D. (2007) Empirical features of congested traffic states and their implications for traffic modeling. Transportation Science 41(2):135-166

5. Brilon W., Geistefeldt J., Regler M. (2005) Reliability of freeway traffic flow: A stochastic concept of capacity. In: Proceedings of the 16th International Symposium on Transportation and Traffic Theory. pp 125-144

6. Elefteriadou L., Roess R. P., McShane W. R. (1995) Probabilistic nature of breakdown at freeway merge junctions. Transportation Research Record 1484:80-89

7. van Essen H., van Wijngaarden L., Schroten A., Sutter D., Bieler C., Maffii S., Brambilla M., Fiorello D., Fermi F., Parolin R., Beyrouty K. E. (2020) Handbook on the external costs of transport Version 2019-1.1. Publications Office of the European Union, Luxembourg

8. Arnott R., de Palma A., Lindsey R. (1990) Economics of a bottleneck. Journal of Urban Economics 27:111-130

9. Arnott R., de Palma A., Lindsey R. (1993) A structural model of peak-period congestion: A traffic bottleneck with elastic demand. American Economic Review 83(1):161-179

10. Small K. A. (2015) The bottleneck model: an assessment and interpretation. Economics of Transportation 4(1-2):110-117

11. Vickrey W. S. (1969) Congestion theory and transport investment. American Economic Review 59:251-261

12. Xiao L.-L., Huang H.-J., Liu R. (2015) Congestion behavior and tolls in a bottleneck model with stochastic capacity. Transportation Science 49(1):46-65

13. Yang H., Hai-Jun H. (1997) Analysis of the time-varying pricing of a bottleneck with elastic demand using optimal control theory. Transportation Research Part B: Methodological 31(6):425-440
14. Hall J. D. (2018) Pareto improvements from Lexus lanes: The effects of pricing a portion of the lanes on congested highways. Journal of Public Economics 158:113-125

15. Hall J. D., Savage I. (2019) Tolling roads to improve reliability. Journal of Urban Economics 113:103187

16. Arnott R. (2013) A bathtub model of downtown traffic congestion. Journal of Urban Economics 76(1):110-121

17. Arnott R., Kokoza A., Naji M. (2016) Equilibrium traffic dynamics in a bathtub model: A special case. Economics of Transportation 7-8:38-52

18. Fosgerau M. (2015) Congestion in the bathtub. Economics of Transportation 4(4):241-255

19. Fosgerau M., Small K. A. (2013) Hypercongestion in downtown metropolis. Journal of Urban Economics 76(1):122-134

20. Johnson M. B., 1964 On the economics of road congestion. Econometrica 32:137-150

21. Pigou A. C. (1920) The Economics of Welfare. Macmillan, London

22. Walters A. A. (1961) The theory and measurement of private and social cost of highway congestion. Econometrica 29(4):676-699

23. Goldmann K., Sieg G. (2020) Economic implications of phantom traffic jams: evidence from traffic experiments. Transportation Letters 12(6):386-390

24. He X., Chen X., Xiong C., Zhu Z., Zhang L. (2016) Optimal time-varying pricing for toll roads under multiple objectives: A simulation-based opimization approach. Transportation Science 51(2):412-426

25. Frascaria D., Olver N., Verhoef E. T. (2020) Emergent hypercongestion in Vickrey bottleneck networks. Transportation Research Part B: Methodological 139(523-538):241-247

26. Verhoef E. T. (1999) Time, speeds, flows and densities in static models of road traffic congestion and congestion pricing. Regional Science and Urban Economics 29(3):341-369

27. Verhoef E. T. (2005) Speed-flow relations and cost functions for congested traffic theory and empirical analysis. Transportation Research Part A 39:792-812

28. Brilon W., Geistefeldt J., Zurlinden H. (2007) Implementing the concept of reliability for highway capacity analysis. Transportation Research Record 2027:1-8

29. Brilon W., Geistefeldt J. (2010) Überprüfung der Bemessungswerte der HBS für Autobahnabschnitte außerhalb der Knotenpunkte. Forsch Straßenbau Straßenverkehrstechnik 1033:1-52

30. Yuan K., Knoop V. L., Leclercq L., Hoogendoorn S. P. (2017) Capacity drop: a comparison between stop-and-go wave and standing queue at lane-drop bottleneck. Transportmetrica B: Transport Dynamics 5(2):145-158

31. Batley R., Bates J., Bliemer M., Börjesson M., Bourdon J., Cabral M., Chintakayala P., Choudhury C., Daly A., Dekker T., Drivyla E., Fowkes T., Hess S., Heywood C., Johnson D., Laird J., Mackie P., Parkin J., Sanders S., Sheldon R., Wardman M., Worsley T. (2019) New appraisal values of travel time saving and reliability in Great Britain. Transportation 46(3):583-621

32. Hössinger R., Aschauer F., Jara-Díaz S., Jokubauskaite S., Schmid B., Peer S., Axhausen K., Gerike R. (2020) A joint time-assignment and expenditureallocation model: value of leisure and value of time assigned to travel for specific population segments. Transportation 47(3):1439-1475

33. Small K., Winston C., Yan J. (2005) Uncovering the distribution of motorists' preferences for travel time and reliability. Econometrica 73(4):1367-1382

34. Brilon W., Geistefeldt J. (2009) Paper presented at the 2 ISFO (International Symposium on Freeway and Tollway Operations), Honolulu

35. Geistefeldt J. (2016) Assessment of basic freeway segments in the German Highway Capacity Manual HBS 2015 and beyond. Transportation Research Procedia 15:417-425

36. Taylor N. B., Bourne N., Notley S. O., Skrobanski G. (2008) Evidence for speed flow relationships. In: (Proceedings) European Transport Conference 2008. pp 1-19

37. Hranac R., Sterzin E., Krechmer D., Rakha H., Farzaneh M. (2006) Empirical studies on traffic flow in inclement weather. U.S Department of Transportation - Federal Highway Administration

38. Rakha H. (2009) Validation of van Aerde's simplified steady-state car-following and traffic stream model. Transportation Letters: The International Journal of Transportation Research 1:225-242

39. van Aerde M. (1995) Single regime speed-flow-density relationship for congested and uncongested highways. Presented the 74th TRB annual conference, Paper no. 950802, Washington D.C. 
40. Peer S., Koopmans C. C., Verhoef E. T. (2012) Prediction of travel time variability for cost-benefit analysis. Transportation Research Part A 46(1):79-90

41. Arnese P., Hjelkrem O. A. (2018) An estimator for traffic breakdown probability based on classification of transitional breakdown events. Transportation Science 52(3):593-602

42. Lorenz M., Elefteriadou L. (2000) A probabilistic approach to defining freeway capacity and breakdown. In: Transportation Research Circular EC018: 4th International Symposium on Highway Capacity, Conference Proceedings. pp 84-95

43. Kaplan E. L., Meier P. (1958) Nonparametric estimation from incomplete observations. Journal of the American Statistical Association 53(282):457-481

44. Tu H., Li H., van Lint H., van Zuylen H. (2012) Modeling travel time reliability of freeways using risk assessment techniques. Transportation Research Part A 46:1528-1540

45. Calvert S. C., Snelder M. (2016) Influence of weather on traffic flow: an extensive stochastic multi-effect capacity and demand analysis. EuropeanTransport 60:1-24

46. Hall F. L., Agyemang-Duah K. (1991) Freeway capacity drop and the definition of capacity. Transportation Research Record 1320:91-98

47. Treiber M., Kesting A. (2013) Traffic Flow Dynamics. Springer, Berlin Heidelberg

48. Chen D., Ahn S., Laval J., Zheng Z. (2014) On the periodicity of traffic oscillations and capacity drop: The role of driver characteristics. Transportation Research Part B 59:117-136

49. Chung K., Rudjanakanoknad J., Cassidy M. J. (2007) Relation between traffic density and capacity drop at three freeway bottlenecks. Transportation Research Part B: Methodological 41:82-95

50. Srivastava A., Geroliminis N. (2013) Empirical observations of capacity drop in freeway merges with ramp control and integration in a first-order model. Transportation Research Part C 30:161-177

51. Highway Capacity Manual (2016) A Guide for Multimodal Mobility Analysis. 6th Edition, Washington

52. Ponzlet M. (1996) Auswirkungen von systematischen und umfeldbedingten Schwankungen des Geschwindigkeitsverhaltens und deren Beschreibung in Verkehrsflussmodellen. Lehrstuhl für Verkehrswesen Ruhr-Universität Bochum, Issue 16

53. Brilon W., Lohoff J. (2011) Speed-flow models for freeways. Procedia Social and Behavioral Sciences 16:26-36

54. BaSt (2012) Zeitbewertung in ökonomischen Planungsrechnungen. Bundesanstalt für Straßenwesen, Bergisch Gladbach

55. Abrantes P. A., Wardman M. R. (2011) Meta-analysis of UK values of travel time: An update. Transportation Research Part A: Policy and Practice 45(1):1-17

56. Hensher D. A. (2011) Valuation of travel time savings. In: de Palma A., Lindsey R., Quinet E. (eds). A Handbook of Transport Economics. Edwad Elgar Publishing, Cheltenham, Northampton. pp 135-259

57. Mishra S., Tang L., Ghader S., Mahapatra S., Zhang L. (2018) Estimation and valuation of travel time reliability for transportation planning applications. Case Studies on Transport Policy 6(1):51-62

58. Aarts L., van Schagen I. (2006) Driving speed and the risk of road crashes: A review. Accident Analysis and Prevention 38(2):215-224

59. Ntziachristos L., Samaras Z. (2000) Speed-dependent representative emission factors for catalyst passenger cars and influencing parameters. Atmospheric Environment 34(27):4611-4619

60. Tscharaktschiew S. (2020) Why are highway speed limits really justified? An equilibrium speed choice analysis. Transportation Research Part B: Methodological 138:317-351

61. Friedrich B. (2016) The effect of autonomous vehicles on traffic. In: Maurer M., Gerdes J., Lenz B., Winner H. (eds). Autonomous Driving: Technical, Legal and Social Aspects. Springer, Berlin Heidelberg. pp 317-334

62. Utesch F., Brandies A., Pekezou Fouopi P., SchießI C. (2020) Towards behaviour based testing to understand the black box of autonomous cars. European Transport Research Review 12(1):48

63. Verhoef E. T., Rouwendal J., Rietveld P. (1999) Congestion caused by speed differences. Journal of Urban Economics 45(3):533-556

64. Coifman B. (54) Empirical flow-density and speed-spacing relationships: Evidence of vehicle length dependency. Transportation Research Part B: Methodological 78
65. BMVI (2016) Methodenhandbuch zum Bundesverkehrswegeplan 2030. Federal Ministry of Transport and Digital Infrastructure, Karlsruhe, Berlin Waldkirch, München

66. Infas, DLR (2010) Mobilität in Deutschland 2008, Ergebnisbericht: Struktur - Aufkommen - Emissionen - Trends, Bonn, Berlin. https://www.bmvi.de/ SharedDocs/DE/Anlage/NerkehrUndMobilitaet/mid-2008ergebnisbericht.pdf

\section{Publisher's Note}

Springer Nature remains neutral with regard to jurisdictional claims in published maps and institutional affiliations.

\section{Submit your manuscript to a SpringerOpen ${ }^{\circ}$ journal and benefit from:}

- Convenient online submission

- Rigorous peer review

- Open access: articles freely available online

- High visibility within the field

- Retaining the copyright to your article

Submit your next manuscript at $>$ springeropen.com 